\title{
Suggestive Resources of Complex Verbal Models
}

\author{
Tatiana Rogozhnikova* \\ Department of Language Communication and Psycholinguistics, Ufa, State Aviation Technical University, Ufa, Russia
}

\begin{abstract}
The article describes the results obtained in the decoding process of the suggestive potential of verbal models. A verbal model is defined by the author as a materialised model of any complexity level (sound-letter, word, text), bearing an inner form through the outer manifestation of which latent information content and resource of impact of a particular model is implemented. Any text is considered as a "translator" from the language of idiostates to the language of reality control. For the article the author has selected the examples which are centered around the texts written by N. I. Bukharin during the most complicated period of his life. The author discussed the dramatic result of the collision of two and more suggestions: suggestively strong intense texts created by N. I. Bukharin and the Powers reaction on them. One more group of the analyzed texts covers the quatrains (mantras), which were used for preparing warriors in medieval China. The author has made the model of the suggestive effect trajectory of sound-resonant sets of the given quatrains and has traced the picture of unusual brain rhythmic activity which appears in the course of the intensive multiple repeating of the texts by the training recruits.
\end{abstract}

\section{Introduction}

The verbal model of any degree of complexity (a soundletter, word or text) possesses a suggestive potential of a different level. The potential level can be measured and expressed in quantitative and qualitative indices.

The results of studying the concept of suggestion from the point of view of medicine and psychology made it possible to acknowledge the word as the signal of signals capable of replacing the effects of any physical stimuli. We can only regret the fact that the linguistic achievements in latent verbal mechanisms comprehension have not been so significant up to now. There are still some questions as to how to measure the power of word/text effects, how to determine its qualities and what analytical units can be applied in decoding the suggestibility of language phenomena.

Scientists often reproach scholars for the absence of the objective methods of data analysis. Those reproaches are just in many ways if we speak about the traditional linguistic approach to the language phenomena analysis which is oriented towards the descriptive model of a language as a stable "solid" product based on the linguistic world-image which is derived from language units by way of logical-rational analysis of vocabulary units and texts. Such reproaches lose their power as soon as we approach a human's speech organization as a self-organized system, as a dynamic functioning system, which state is characterized by constant interaction between the process of speech event analysis and arrangement and its product.
Modern linguistics and psycholinguistics in their complexity can easily compete with mathematics and physics.

We started the work on creating formalized research algorithms for studying the suggestive (affecting) resources of verbal models in 2005 [1: 96-103] with the attempt to analyze the arsenal of analytical units, by which we can decode the latent potential of a soundletter, word or text. We are talking about absolutely special units of the analysis for exploring hidden reserves, as the absence of language manifestations of these inner forms is unable to analyze by traditional linguistic methods. The article describes the results obtained in the decoding process of the suggestive potential of different complex verbal models.

The directions in which the impact potential can be decoded and "power of a word" can be measured are discussed in the study. The author has identified eight tools for suggestive potential investigation. The first tool aims at studying rhythmic activity of the brain while presenting verbal stimuli. The second one relates to the analysis of psychosemantics of colour and associative colour of models. The third one bases on possible analogies with the models used in quantum physics. The fourth instrument is oriented on the analysis of language phenomena in the context of different perception modalities. The fifth one focuses on ranking emotionalevaluative features characteristic of verbal model. The sixth one touches upon the rhythmic organisation and rhythmic codes of the models. Suggestive resources of musical discourse are formed by the seventh tool frame. The eighth one focuses on gender identification in the text.

Corresponding author: burzian@yandex.ru 
Any text is considered by the author as a "translator" from the language of idiostates to the language of reality control. For this article we have selected the examples which are centered around the 10 texts written by N.I. Bukharin during the most complicated period of his life. The analysed texts cover the period from 27 August 1936, when N.I. Bukharin began feeling concerned about his life, up to 14 March 1938, the last day before the execution. We discussed the dramatic result of the collision of two and more suggestions: suggestively strong intense texts created by N.I. Bukharin and the authorities' reaction to them. One more group of the analysed texts covers the 32 quatrains (mantras), which were used for warrior training in medieval China. The model of the suggestive effect trajectory of soundresonant sets of the given quatrains has been made during the investigation. We have traced the picture of unusual brain rhythmic activity which appears in the course of the intensive multiple repeating of the texts by the training recruits. It is possible that particularly such stress-texts, creating a state of tension, emotional excitement, irritation and unconscious anger are able to play a crucial part in a fast training of a super warrior.

\section{Basic concepts}

The experimental data, laboratorial and clinical research provide the possibility to correctly evaluate the meaning of a word as a physiological factor [2]. The research indicates that the word is far from being indifferent for a human organism under certain conditions they may cause certain changes depending on its semantic meaning [Ibid]. K.I. Platonov remarks that in their joint operation the first and the second signal system are involved into regulation not only of the external but the whole internal vegetative activity of a human organism ensuring its dynamic coherence. The speech system causes most diverse reactions which are objectively registered. But even now, as stated by the author, we cannot sufficiently evaluate the actual influence of verbal stimulations on deep and hidden physiological processes.

The delivery of a word/text causes a particular type of vibrations which initiate physiological processes. "It is the delivery that causes the vibrations forming the beginning of one or another physiological process" [3: 9]. Creating different vibrations, a person approbates a physical process different from one that emerged during vibrations have already emerged in the organism and experienced by it. This "new" physiological process will have its effect not only on him but also on everything around [4].

Most different diverse verbal material was subjected to the analysis [5].

Studying the suggestive potential of a name, we reviewed its politically alternative name and analyzed deep parameters of "suggestive successfulness" or "unsuccessfulness" of such verbal camouflage on the basis of certain party pseudonyms and nicknames. Quatrains (mantras) used for warrior training in medieval China were analyzed. The author studied prayer texts in Russians, Bashkir and Tartar languages as well as incantations, curses and charms and so forth. Special attention was paid to speeches of political figures written by them in difficult and crucial moments when significant mental and emotional concentration was required to persuade the recipient of the text.

Through the article, we shall give examples unfolding certain aspects of suggestive capability of a verbal model.

First of all, the notions and research fields allowing us to form tools of the analysis need to be clarified. Suggestive potential is interpreted by us as the "the verbal model power" that can be decoded and measured. In this context we believe that the suggestive potential correlates with the inner form of the verbal model. The inner form and the suggestive potential are associative in their nature. The suggestive potential being realised in the social speech through sonic resonant vibrations of the text creates a mental image which becomes an influencing factor. The degree of suggestive influence is different for sonic resonant lines of different model but all of them exert influence over psychomotor system of a human being. Neurophysiologic nature of the association mechanism, effective functioning of which contributes to language learning, makes it responsible not only for the processes of speech organisation functioning but for many other vital processes of a human being including the evolution of the human consciousness. Associative activity in this context represents a universal dynamic principle with great suggestive capabilities. Verbal model - a model of any complexity (sound-letter, word, text), which is the carrier of the inner form through the manifestations of which latent informativity and influence potential of the certain model are realised. Suggestive resources are understood as summation of all influencing elements possessed by the exact model and are judged with the help of analytical (psychometric) units, revealed for the levels allowing us to perform measurements, correlate the showings and compare indications.

We have already mentioned the eight tools for suggestive potential investigation identified by the author. The first tool is related to the studies of rhythmic activity of the brain while presenting verbal stimuli (works by T.M. Rogozhnikova). The second one is connected with the research in phonosemantics, psychosemantics of colour and sound-colour potential (T.M. Rogozhnikova, N.V. Efimenko, G.R. Kochetova, D.D. Kudashov, R.V. Yakovleva). The third tool is based upon the possible analogy with models used in quantum physics. If "vector of state", representing a sum of mutually exclusive base states, forms the basis of the full description of a phenomenon then it is possible to choose a particular case of the vector of state as superposition for the two mutually exclusive states (T.M. Rogozhnikova, R.A. Daminova). The fourth one is oriented on the analysis of language phenomena in the context of different perception modalities, which allows us to reveal changes in the perception models and coding the information about the surrounding world (works by T.M. Rogozhnikova and A.I. Navalikhina). The fifth one is related with ranking emotional-evaluative features 
characterising the verbal model and highlighting special linguistic units of the text, which code and decode the suggestive charge of the given verbal model with greater probability (T.M. Rogozhnikova, R.V. Yakovleva). The sixth one touches upon the rhythmic organisation and rhythmic codes of the verbal models (T.M. Rogozhnikova, L.V. Kishalova). We assume that texts with a different rhythmic structure possess different suggestive potential. A conventional border may be drawn between the texts with high, medium and low rhythmicity. This assumption is based on the specificity of our consciousness which is according to W. Wundt rhythmic in its nature. This phenomenon is tightly connected with the whole of our psychological organisation. The consciousness is rhythmic because the whole our body is rhythmic [6: 213] Suggestive resources of the musical discourse form the seventh tool's framework. Through the experimental procedures of establishing associated colority of the note alphabet the latent influence potential and informativity of musical models are determined, associative colour matrix of the note alphabet is structured and the algorithm of automated analysis of the associative colority of the note discourse is created by the authors (research by T.M. Rogozhnikova, I.V. Bogoslovskaya, D.D. Kudashov). The eighth one focuses on gender identification in the text. Partly this approach (as in case of rhythmic organisation investigation and rhythmic codes of verbal models) may be viewed as one of the steps in authorship attribution of a text as it touches upon a problem of linguistic consciousness organisation on the gender basis. The first steps in that direction deal with issues of creating a mathematical model for the text's information redundancy (T.M. Rogozhnikova, N.N. Voronov).

\section{Discussion}

Any verbal model can be analyzed within the framework of one or several approaches. Today we have at our disposal six computer programs allowing us to judge about the associative (psychological) colority of a text, differences of the given text from statistically average language colority model, ranking of the text indications according to bipolar scales, brain rhythms activated by the text, text's rhythmical structure or its "pulse", quantitative composition and frequency of letter-sounds' emergence and their summation, quality of the text's influence (mild, neutral, hard), "power" indications of that influence and its "charge" - positive/negative, emotional background of the text and its constituents' ranking. We also possess data on lexical and grammatical composition of the text, capabilities to calculate the golden section of the text and create static and dynamic color images of a given verbal model.

The developed instrumentarium allows us to decode influence potential and latent informativity of a text without linguistic manifestations of these inner forms, which cannot be analysed through traditional linguistic methods.
Let us give some examples. If we use results of the brain rhythmic activity as analytical units, we will deal with alpha-beta-theta-delta texts which cause brain rhythmic activity with domination of certain brain rhythm. In this case various results are possible, their scale comprising 11 states: 4 states with negative vector (minus-texts); four states with positive vector (plustexts); synchronisation of bio-potentials marked with "plus" (ideal texts); hard negative influence ("horror stories for various purposes"); neutral position without suggestion (neutral texts). Such variety of texts with reference to the brain electric activity is found in the works by I.Yu. Cherepanova [see: 7].

The above said is illustrated by a fragment of the analysis of 32 quatrains (mantras), which were used for warrior training in medieval China. In the XVI century a methodology which became the basis for further development of wushu was created. As it is described by I.A. Voronov in his book the methodology was created by the talented military leader Qi Jiguang (1528-1587) on the basis of empirical knowledge of the psychomotor mechanisms of human organism and the structure of a person. In certain conditions this methodology made it possible to get warriors ready for fighting within the shortest time possible (3-10 days). "In the middle of XVI century this warlord ("general") commanded a corps of 32 thousand men. For the recruit training in basics of military maneuver Qi Jiguang wrote a treatise which he called "The New Treatise on Military Efficiency" ("Ji Xiao Xin Shu") [8: 355]. The technique was based on psychomotor gymnastics "dao-yin" but all the moves are performed simultaneously with choral articulation of the 32 quatrains, describing these moves and images associated with them. The use of sound resonant lines during the warrior conditioning while training in movement action are of great interest. We tried to model the trajectory of the suggestive influence of sound resonant lines of the given quatrains.

In brief let us remind the technology of training which is given in the article [9]. According to witness description, the soldier's training according to this methodology was as follows: Shi-Fu (instructing commanders) made the recruits recite the texts containing 8-20 hieroglyphs keeping eyes shut (for the perception of thought images). These texts were read, as it was said in ancient Chinese treatises "from dawn till dusk and after dusk until the consciousness is lost". Then the recruits laid on the ground in rows and after some time leapt to their feet calling out names of heroes of ancient dynasties. After that, they started to exercise warrior moves closing in on each other then moving away. Some of them held bamboo poles, pikes or halberds, or swords and sabres. Dispersing in mountain passes and gorges they went on rampage turning everything upside down. When the complex came to the finish, they approached the commander and inquired: "Lao-shi-fu! I ask for permission to return". And they came out of trance (in which they were for 10 days of training, embodying psychologically one of the heroes of previous battles, returning now to their normal state). After that, they did not lie on the back and did not close their eyes. As soon as they repeated the spell once more 
they could immediately fistfight, their body became flexible, jumps higher. The training is more effective for juveniles (Yi-he-tuan, 1955) [quot.: 9: 163].

The words of the Chinese graphical system transliterated using means of the Russian graphical one were analysed letter-by-letter. Translations into Russian were not analysed. All 32 quatrains were borrowed from the book [8].

Analysis drew a picture of uncommon rhythmic activity. The first 7 quatrains activate theta-minus rhythm; 8th mantra - alpha-minus rhythm; from 9th to 18th theta-minus rhythm is registered; from 19th to $21 \mathrm{st}$ - alpha-minus rhythm; 22nd - theta-minus rhythm; 23rd - alpha-plus rhythm (high indicators); 24th - alpha-minus rhythm; 25th - theta-minus; 26th - alpha-minus; 27th theta-minus; 28th - alpha-minus; 29th - theta-minus; 30th - alpha-minus; 31st - alpha-minus; 32nd - alphaminus rhythms. Out of 32 quatrains $21(66 \%)$ cause theta-minus rhythm moreover this rhythm is consequently activated during the range of quatrains (from 1st to 7th and from 9th to 18th that is we see long stretches with active theta-minus rhythm which are sporadically interrupted by activation of another rhythm). It should be noted that even in these rhythm change some regularities are observed. Firstly, only two interchanging minus-rhythms are registered (theta-minus may be viewed as primary and alpha-minus rhythm emerging only in a few mantras). The 23rd mantra activates alpha-plus rhythm.

Grey Walter, English neurophysiologist and cyberneticist linked theta-rhythms with emotional states of a person. During clinical tests, theta-rhythms were defined as rhythms specific for certain states. Thetarhythms according to the scientist's observations are somehow subtly connected with the feelings of pleasure and pain. "Theta-rhythms connection with hypothalamus and structures around third ventricle of cerebrum was finally proved by Denis Hill during his studies of aggressive psychopath" [10: 215]. The author mentioned by G. Walter singled out a group of the afflicted with evident sparks of slow theta-vibrations of special character - "psychopaths with disrhythmic aggressive behaviour". Such afflicted periodically had episodes with furious assaults on living beings with intention to take away life. Such destructive homicidal episodes were mostly or totally unprovoked.

There are grounds to assume that quatrains activating theta-rhythms and causing the lust for acts of destruction performed by recruits with no obstructions in mountain passes and gorges drove them into a trance-like state during which they went on rampage turning everything upside down. This state of trance with the critical thinking being "turned off" together with full concentration on words of the spell and those images caused by it will contribute to achievement of victories by such warriors on the battlefield.

Theta-rhythm as a materialised emotional correlate may serve, judging by the success of implementation of sound resonant lines by the example of troop training of the military leader Qi Jiguang, as an indication of the degree of emotional suggestive influence of a verbal model upon the psychomotor system of a human. At the same time the verbal model describing the motor action and thought-image associated with it becomes the influencing factor itself. And perhaps it is theta-minus texts that are able to play the decisive role in the training of a super-warrior. Stress-texts creating states of tension emotional excitement, irritation and subconscious anger, proved to be able to exert focused influence upon the psychomotor system of a person and to form professionally important qualities for a warrior.

Let us give another example related with the rhythmic brain activity: 10 texts written by N.I. Bukharin in the most difficult period of his life when he was in the state of extreme emotional strain, dismay and fears for his life. Some of them were written by him while he was placed into the NKVD inner prison hoping but at the same time not believing that his life would be spared. These texts among which were his letters, pleas for mercy and his last public speech (his final speech) were written and spoken before his death.

N.I. Bukharin was shot on the 15th of March 1938. Chronologically the analysed texts cover the time period from the 28th of August 1936, when the author clearly saw that his life is threatened, to the 14th of March 1938, the last day before his execution. The volume of the material for analysis is 88500 of printed characters. For the sake of convenience, the texts are enumerated as follows.

Text 1 - "To all members of the $\operatorname{VKP}(b)$ Central Committee Politburo. Copy for comrade Vyshinsky dated 27 August 1936.

Text 2 - Letter to K.Ye. Voroshilov dated 31 August 1936.

Text 3 - Letter to K.Ye. Voroshilov dated 03 September 1936.

Text 4 - "To the future generation of the party leadership". The last letter of N.I. Bukharin, February 1937.

Text 5 - Letter to I.V. Stalin dated 15 April 1937.

Text 6 - Letter to I.V. Stalin dated 10 December 1937.

Text 7 - Letter to A.M. Larina dated 15 January 1938.

Text 8 - The final speech of N.I. Bukharin during Bukharinist-Trotskyite trial. Evening session of 12 March 1938.

Text 9 - Petition for pardon (To the Presidium of the Supreme Soviet of the USSR from sentenced to be shot N.I. Bukharin) dated 13 March 1938.

Text 10 - Petition for pardon (To the Presidium of the Supreme Soviet of the USSR from sentenced to be shot N.I. Bukharin) dated 14 March 1938.

All texts (except Text 7 - the letter to his wife) are characterised by indications of "ideal complex influence", which is realised through the state of total synchronisation of brain's bio-potentials. We cannot judge the physiological significance of the synchronicity of the cerebral processes, but we can assume that such synchronicity of the bio-potentials' vibrations reflect real (physical and emotional) conditions which become necessary to establish connections between 
corresponding regions of the brain. Desynchronisation of bio-potentials in the cerebral cortex generally emerges as a reaction to various stimulations or as response to the effect of pharmacological agents (we skip in this case the cases of desynchronisation during special stages of sleep - the so-called "fast sleep"). In this case N.I. Bukharin's capability to produce influentially "ideal" text is wondrous, especially if circumstances and the conditions these circumstances caused are taken into consideration.

The picture changes dramatically when we analyse the texts by other political persons, whose fates were also not easy but developed differently. We performed comparative analysis of texts written at various periods by V.I. Lenin, I.V. Stalin, L.D. Trotsky, L.P. Beria, A.Ya. Vyshinsky, G.M. Malenkov, V.M. Molotov and others. The texts created by these authors are characterised exceptionally various indications of domination of one or another brain rhythm, however, we have never faced such "ideal" similarity, created by one person, in our analytical practice. The analysis of a large amount of texts shows that verbal models having an "ideal complex impact" are rarely present. It takes significant effort to intentionally and purposefully create them; it is a rather painstaking task. Such product can be produced spontaneously during emotional uplift marked by positive emotions or during some special psychic state of a person characterised by acute rise of the internal activity of the person, spiritual and physical exertion. In difficult and hard situations connected with danger and alarm, a text with such traits is more of exception. We met such exceptions when analysed the speeches of politicians who were close to I.V. Stalin during his funeral. Eulogies near the leader's coffin made by L.P. Beria, G.M. Malenkov, V.M. Molotov are characterised not only by ideal complex influence but an original text indications. All eulogies are characterised on the deeper level as "exalted", "lightful", "joyful", "beautiful", but at the same time the indication "sinister" is registered as significant. On the surface (materialised) level the text narrates about a mournful for the whole country event, grave loss, but on deeper level indications of a quite different state are found which is conveyed by the created text. Some controversy arises between the real situation, which should by common sense logic be reflected by the emotional state similar to the situation, and the mismatched psychic state.

Indications of the verbal model, causing particular emotional state, may be taken as the units of analysis. Capabilities of the programmes developed by us allow performing indication analysis of a text of any volume and genre during which dominating (significant, prominent, strong) and peripheral (lightly expressed, weak) indications of the text are reviewed according to various scales. Indication scales devised by A.P. Zhuravlyov (the bipolar scale consisting of 25 indications and monopolar scale - of 20) were taken as the basis [11]. Under the dominating or the strong indications, we understand high results of average value received by division of sum of all indications of all of text's letter-sounds by their number. Under lightly expressed indications, we understand low results of average values. The conventional border between the positive and negative value of an indication is the neutral zero position. All indications above zero have positive value and below zero - negative value of the indication.

The dominant indications of the texts according to the monopolar scale were found to be "exalted", "bright", "joyful", "beautiful". The conducted texts' analysis allows us to say that a single person wrote them. Nine out of ten relays similar psychic state of the author although texts were creating under different conditions. The text "Letter to the wife" is different from other texts in several indications. This text is "truthful", "nonaggressive" with these indications having high results. Let us compare the data in table 1.

Table 1. Indications "truthfulness" and "aggressiveness" in the texts by Bukharin.

\begin{tabular}{|c|c|c|}
\hline № text/indication & «truthfulness» & «aggressiveness» \\
\hline Text 1 & Minus 5.0 & Plus 0.4 \\
\hline Text 2 & Minus 0.2 & Minus 1.2 \\
\hline Text 3 & Minus 14.3 & Plus 6.8 \\
\hline Text 4 & Minus 5.0 & Plus 0.7 \\
\hline Text 5 & Plus 0.3 & Plus 2.8 \\
\hline Text 6 & Plus 10.5 & Minus 2.3 \\
\hline $\begin{array}{c}\text { Text 7 (to his } \\
\text { wife) }\end{array}$ & Plus 8.9 & Minus 13.0 \\
\hline Text 8 & Plus 0.3 & Plus 2.8 \\
\hline Text 9 & Plus 7.3 & Minus 0.1 \\
\hline Text 10 & Minus 6.0 & Minus 0.5 \\
\hline & $50 \%$ vs $50 \%$ & $50 \%$ vs $50 \%$ \\
\hline
\end{tabular}

Only three out of ten $(6,7,9)$ are characterised by "correctness" of correlation of these parameters, that is truthful and non-aggressive. While the rest seven are either non-truthful and aggressive or truthful and aggressive or are characterised by other combinations of indicators.

Having carried out the analysis of grammatical content of the texts (by parts of speech), we took notice that verbs are abundant in the reviewed texts. We compare the rate of verbs of other political figures that we have already mentioned in the article, we see that the verbal or "energetic activity" in Bukharin's texts is higher. In table 2 data (in \%) on the number of verbs and nouns in the texts by N.I. Bukharin and other authors are given.

Obviously, it would be wiser to take the same number of each author's texts for the accuracy of a comparative study. It will be possible to do in the future, but anyway, if we compare every single text of Bukharin with ten texts of the other authors, we will see this significant difference in the indicators. 
Table 2. Number of verbs and nouns in the texts by different authors $(\%)$.

\begin{tabular}{|c|c|c|c|c|c|}
\hline $\begin{array}{c}\text { N.I. } \\
\text { Bukhari } \\
\mathrm{n}\end{array}$ & Verbs & Nouns & $\begin{array}{c}\text { Other } \\
\text { authors }\end{array}$ & Verbs & Nouns \\
\hline Text 1 & 8.34 & 11.82 & Lenin (1) & 6.82 & 18.64 \\
\hline Text 2 & 9.1 & 10.57 & Lenin (2) & 6.83 & 17.27 \\
\hline Text 3 & 8.28 & 11.24 & Stalin (1) & 4.74 & 18.75 \\
\hline Text 4 & 6.35 & 19.06 & Stalin (2) & 5.80 & 19.28 \\
\hline Text 5 & 9.47 & 10.67 & Beria & 4.72 & 24.35 \\
\hline Text 6 & 10.17 & 9.19 & Vyshinsky & 7.54 & 14.07 \\
\hline Text 7 & 7.87 & 8.88 & Trotsky & 7.11 & 18.22 \\
\hline Text 8 & 7.25 & 12.81 & Malenkov & 5.18 & 24.94 \\
\hline Text 9 & 7.42 & 17.02 & Molotov & 5.19 & 21.22 \\
\hline Text 10 & 8.26 & 13.51 & Zhdanov & 5.36 & 22.69 \\
\hline $\begin{array}{c}\text { simple } \\
\text { average }\end{array}$ & $\mathbf{8 . 2 5}$ & $\mathbf{1 2 . 5}$ & $\begin{array}{l}\text { simple } \\
\text { average }\end{array}$ & $\mathbf{5 . 9}$ & $\mathbf{1 9 . 9}$ \\
\hline
\end{tabular}

Associative colority of a verbal model as a tool has significant capabilities. Sound-letter units of a graphic sound system are particularly convenient mostly because of their determined quantity which allows calculating of all possible combinations, model and program data, create automated information systems. For these purposes, the following computer programmes were created: BARIN (Russians, English); BATYR (Bashkir, Tartar, Russian); Bürger (German, Russian). Ability to work with virtually any language is one of the positive aspects. For a speaker the sound becomes perceived only after being referred to a particular letter. That is why the unknown set of sounds perceived only phonetically without being supported by a visual image of a letter does not provide us with the complete picture because of the minimal differences in indication cover.

The dominant colour of the analysed texts by N.I. Bukharin turned out to be blue, red and white. When compared with the statistically average model of associative colority received through another programme - SCHETOVOD 2014 (authored by T.M. Rogozhnikova and D.D. Kudashov) it was found out that the author's texts are "more blue", "more white" and "less red". The statistically average or "standard" colour model of the language was created on the basis of establishing the frequency of letter-sounds of the language through the analysis of over six million sound-letters of texts belonging to various genres. Consequently a database was accumulated and average colour model was constructed basing on the frequency of a sound-letter. For the standard model the level of blue is $22.5 \%$, red $16.2 \%$, white - $14,4 \%$. In summary Table 3 there are represented the indicators of the associative coloring of all ten Bukharin's texts. Let us conventionally call these data "the associative coloring of a core zone". We can see in Table 3 that the "norms" of associative blue and white colors are significantly exceeded.

Table 3. Indications of associative colority of the texts by N.I. Bukharin (dominant colours rate without periphery).

\begin{tabular}{|c|c|c|c|}
\hline Text/Colour & $\begin{array}{c}\text { Blue } \\
\text { (standard- } \\
\mathbf{2 2 , 5 \%}\end{array}$ & $\begin{array}{c}\text { White } \\
\text { (standard }- \\
\mathbf{1 4 , 4 \%})\end{array}$ & $\begin{array}{c}\text { Red } \\
\text { (standard } \\
\mathbf{1 6 , 2} \%)\end{array}$ \\
\hline Text 1 & 23.9 & 14.8 & 15.2 \\
\hline Text 2 & 23.9 & 14.5 & 14.9 \\
\hline Text 3 & 22.3 & 16.3 & 13.2 \\
\hline Text 4 & 24.0 & 14.6 & 14.6 \\
\hline Text 5 & 23.6 & 15.7 & 14.2 \\
\hline Text 6 & 23.3 & 15.4 & 14.1 \\
\hline Text 7 (wife) & $\mathbf{2 1 . 3}$ & 16.0 & 14.2 \\
\hline Text 8 & 24.1 & 14.6 & 15.4 \\
\hline Text 9 & 25.6 & 17.3 & 13.7 \\
\hline Text 10 & 23.0 & 15.9 & 14.5 \\
\hline $\begin{array}{c}\text { simple } \\
\text { average }\end{array}$ & $\mathbf{2 3 . 5}$ & $\mathbf{1 5 . 5}$ & $\mathbf{1 4 . 4}$ \\
\hline
\end{tabular}

During the investigation of suggestive resources of verbal models, the tool employing rhythmic structure of the text turned out to be promising. To enable the analysis of rhythmic characteristics of texts a collective of authors (T.M. Rogozhnikova, L.V. Kishalova, A.E. Kishalov) developed the computer programme PULS 2015 to process rhythm of a prose text. The programme was based upon the System Automated Modelling of Complex Technical Objects (SAMCTO), developed by I.A. Krivosheyev, D.A. Akhmetzyanov, D.G. Kozhinov (Certificate of official registration, Rospatent №2011611712, Moscow, 2011).

Interchange of rhythmic units creates a certain overrhythm and their sum creates a rhythmic structure of the text. Results of the automated analysis of a text are graphically displayed using the programme: in Cartesian coordinate system on the axis $\mathrm{X}$ the counting number of interstress interval in the linear series of a text, on the axis $\mathrm{Y}$ the number of unstressed vowels is displayed.

Let us review the rhythmic structure of the letter by N.I. Bukharin to K.E. Voroshilov (Text 2). The main syllable accented over-rhythm (mean-squared deviation which allow us to label the text as "smooth" or "ragged") is 1,4021, which is above the norm. For a literary text in Russian the mean-squared deviation lies between 0,9 and 1,4 (according to data collected by G.N. Ivanova-Loukyanova). This urges us to classify the text as "ragged".

Text 2 (Fig. 1) is characterised by medium pace or medium general rhythmicity as the simple average of all unstressed syllables as an indicator of text rhythm "speed" equals 2,266. The normal range for "the simple 
average of all unstressed syllables" (average inter-stress interval) indicator lies within 2 and 2,5 syllables.

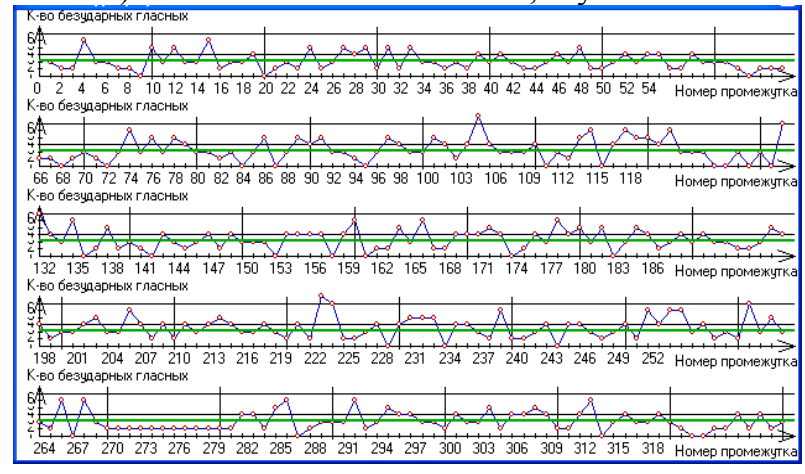

Fig. 1. Rhythmic structure of the letter by N. I. Bukharin to K. E. Voroshilov (Text 2).

If rhythms goes beyond that range then the speed or pace of the text becomes fast (if below 2) or slow (if above 2,5), that is texts with above norm rate have a slow rhythm, with below the norm - fast rhythm. In the analysed texts, we may observe peaks and monotonous depressions reflecting the state of the strongest emotion of the author. The calculations show that these abstracts as a rule are part of the golden section of the text. The golden section of the text is a separate topic to discuss as the principle of the golden section is connected with the highest manifestations of structural and functional perfection of interaction of the whole and its parts in any field.

The analysis of text structure, revealing its "pulsation", allows studying the text as a living being that is able to transmit the condition of the person, who created this living channel.

According to the indications, the texts by N.I. Bukharin may be classified as texts with high suggestive potential. We should assume that the texts with such impact should exercise such kind of influence on the recipient that his mindset as a non-conscious state that is manifested in his readiness to react in a particular way in particular situation, is subject to change (which is a hard but achievable task) or at least a new mindset is to be created (which is a less difficult task with the help of the associative flow emerging during the reading of the texts). But this did not happen. We have a number of conceptions which may be of use in explaining this language-specific psycholinguistic phenomenon which we named as "Bukharin's phenomenon". We refer to the counter-suggestion. As it was mentioned by B.F. Porshnev the break of compelling force of words occurs through counter-suggestion [12: 200].

So, on the one hand, we deal with suggestively strong texts, containing latent energy, on the other hand, we see the dramatic result of the collision of two and more suggestions. B.F. Porshnev wrote that in the physiology of higher nervous activity there is a law of the back induction of impulsion and retardation, i.e. "the excitation focus in the brain cortex is essentially surrounded by retardation "roller", so suggestion, the force of the direct word affecting the mentality, induces (though not automatically) the barrier, formed of $<\ldots>$ different psychic mechanisms" [Op. cit.:192]. Studying these mechanisms, the author points out that suggestion in its pure form (as a definite work of a word) must have had automatic, irresistible or, as psychologists and psychiatrists say, "fatal" character [See ibid.]. As the first phenomenon of protective psychic actions B.F. Porshnev names mistrust, the source of which is the collision of two suggestions.

B.F. Porshnev points out that suggestion, even from a biological point of view, is fraught with danger, as "the force of one organism's impact on the reflexes of another one is so great that technically it can destroy the functioning of any physiological processes, interrupt the meeting of urgent biological needs and to cause death [Op. cit: 195]. And if pure suggestion by its definition contradicts the first-signal system, then a new interference of stopping as a negative reaction to suggestion must appear for their coordination. And the disruption of the compulsive power of a word comes from contrasuggestibility.

It is difficult not to be immune to the texts of N.I. Bukharin, still, they generate mixed feelings.

To summarise, on the one hand, we deal with suggestively strong texts with hidden energies within them; on the other hand, we see the dramatic result of a clash of two or more suggestions. Leaving beyond the scope of the article the historical context, in which the events unfolded and which should be studied by expert historians, we tried to draw attention to the author's texts which broadcasted the transformations of personality under extreme conditions of a clash between suggestions when the reality is controlled by the words whose texts and actions have more suggestive resources, whose counter-suggestion "hacks the compelling force of words".

\section{Conclusion}

There are a lot of difficulties and obstacles on the way from understanding the suggestive potential of a verbal model to the creation of special instruments leading to comprehension of the laws of word and text impact.

"Linguistic intervention" as a part and a parcel of the inevitable convergence process of sciences is becoming quite topical nowadays. By the way of interpenetration, the objects initially of different nature but functioning in similar conditions are getting closer and their proximity can become a component of the evolutionary process reflecting the higher levels of integration. The problems of communication ecology and the ecology of relationship cannot be solved without neurosciences (neuropsychology and neurobiology). And it is hard to do without genetics for there are some genetic basics for the language. Without physiology, linguistics is unable to solve a whole set of problems. The heterogeneous technologies integration leads to the appearance of brand new results dramatically changing the world.

The volume of this publication does not allow us to discuss the matter thoroughly; let it be the topic of the next work to be published.

\section{References}


1. T. M. Rogozhnikova, The Word and the Text: Psycholinguistic Approach. The collection of articles. Tver, Tver State University Press 5, 96-103, (2005)

2. K. I. Platonov, WORD as physiological and healing factor (Medgiz, Moscow, 432, 1957)

3. L. P. Grimak, Magic of biofield: energeticinformational healing (LIBROKOM Publishing House, Moscow, 296, 2013)

4. T. M. Rogozhnikova, Theory and practice of language communication. Proceedings of the $V$ International research and methodological conference. Ufa, Ufa State Aviation Technical University (UGATU), 415-434 (2013)

5. T.M. Rogozhnikov, The Gallery of Associative Portraits, Monograph (Ufa, Ufa State Aviation Technical University (UGATU), 448, (2009)

6. W. Wundt, Awareness and Attention. Anthology on Attention. (Moscow, Moscow State University Press, 385, 1976)

7. I. Yu. Cherepanova, Verbal Suggestion: Theory, Methodology and Psycholinguistic Experiment. $\mathrm{PhD}$ Dissertation (Philology). Perm, 426, (1996)

8. I. A. Voronov, Psychotechnology of eastern martial arts (East Asian classical conception of psychological conditioning of a combatant) (AST publ., Moscow, 432, 2006)

9. I.A. Voronov et al, Abstracts of the 4th Saint Petersburg assembly of young scientists and specialists (Saint Petersburg: Saint Petersburg University Press, 163, 1999)

10. W. Grey Walter, The Living Brain (Norton publ., 1953) (Russ. ed.: Gurvich A.M. Zhivoy mozg (Mir publ., Moscow, 300, 1966)

11. A.P. Zhuravlev, The Phonetic Meaning (Leningrad University Press, Leningrad, 160, 1974)

12. B.F. Porshnev, Historical psychology and social studies 2, 185-219 (2010) 